\title{
Genetic variants associated with lung function: the long life family study
}

\author{
Bharat Thyagarajan ${ }^{1 *}$, Mary Wojczynski ${ }^{2}$, Ryan L Minster ${ }^{3}$, Jason Sanders ${ }^{4}$, Sandra Barral ${ }^{5}$, Lene Christiansen ${ }^{6}$, \\ R Graham Barr ${ }^{7,8}$, CHARGE consortium, SpiroMeta consortium and Anne Newman ${ }^{4}$
}

\begin{abstract}
Background: Reduced forced expiratory volume in 1 second $\left(\mathrm{FEV}_{1}\right)$ and the ratio of $\mathrm{FEV}_{1}$ to forced vital capacity (FVC) are strong predictors of mortality and lung function is higher among individuals with exceptional longevity. However, genetic factors associated with lung function in individuals with exceptional longevity have not been identified.

Method: We conducted a genome wide association study (GWAS) to identify novel genetic variants associated with lung function in the Long Life Family Study (LLFS) $(n=3,899)$. Replication was performed using data from the CHARGE/SpiroMeta consortia. The association between SNPs and FEV $F_{1}$ and FEV $1 / F V C$ was analyzed using a linear mixed effects model adjusted for age, age ${ }^{2}$, sex, height, field center, ancestry principal components and kinship structure to adjust for family relationships separately for ever smokers and never smokers. In the linkage analysis, we used the residuals of the $\mathrm{FEV}_{1}$ and $\mathrm{FEV}_{1} / \mathrm{FVC}$, adjusted for age, sex, height, ancestry principal components (PCs), smoking status, pack-years, and field center.
\end{abstract}

Results: We identified nine SNPs in strong linkage disequilibrium in the CYP2U1 gene to be associated with FEV 1 and a novel SNP (rs889574) associated with FEV $/$ FVC, none of which were replicated in the CHARGE/SpiroMeta consortia. Using linkage analysis, we identified a novel linkage peak in chromosome 2 at $219 \mathrm{cM}$ for $\mathrm{FEV}_{1} / \mathrm{FVC}$ (LOD: 3.29) and confirmed a previously reported linkage peak in chromosome 6 at $28 \mathrm{cM}$ (LOD: 3.33) for FEV ${ }_{1}$.

Conclusion: Future studies need to identify the rare genetic variants underlying the linkage peak in chromosome 6 for $\mathrm{FEV}_{1}$.

Keywords: GWAS, Lung function, Aging

\section{Introduction}

Pulmonary function, as determined by spirometry, indicates the physiological state of the airways and lung. Pulmonary function measures such as forced expiratory volume in one second $\left(\mathrm{FEV}_{1}\right)$, forced vital capacity (FVC) and the ratio of the two measures $\left(\mathrm{FEV}_{1} / \mathrm{FVC}\right)$ are used to diagnose chronic obstructive pulmonary disease (COPD) and assist in the diagnosis of asthma, which are major causes of death and morbidity worldwide [1]. Reduced $\left(\mathrm{FEV}_{1}\right)$ and forced vital capacity (FVC), in healthy asymptomatic adults, are predictors of cardiovascular disease mortality and all cause mortality,

\footnotetext{
*Correspondence: thya0003@umn.edu

'Department of Laboratory Medicine and Pathology, University of Minnesota, 515 Delaware Street SE, 1-136 Moos Towers, Minneapolis, MN 55455, USA Full list of author information is available at the end of the article
}

independent of smoking history [2-9]. The Danish 1905 cohort study also showed that higher $\mathrm{FEV}_{1}$ and peak expiratory flow (PEF) in nonagenarians to be associated with lower mortality [10]. Due to the strong and consistent association with mortality, pulmonary function has been viewed as a biomarker of aging itself [11]. We have previously shown that the prevalence of self-reported COPD was 3 times lower in the Long Life Family Study (LLFS) as compared to the other similarly aged cohorts [12] suggesting that LLFS participants, who were selected for exceptional familial longevity, may have better lung function as compared to the general population. These findings are supported by a previous study that reported male offspring of long lived parents had higher lung function as compared to those with short lived parents [13]. Several studies have shown that pulmonary 
function measures are heritable characteristics with estimates ranging from $38 \%$ for $\mathrm{FEV}_{1}$ to $37 \%$ for $\mathrm{FEV}_{1} / \mathrm{FVC}$ [14-16]. However, the 26 genetic loci associated with $\mathrm{FEV}_{1} / \mathrm{FVC}, \mathrm{FEV}_{1}$ or both (23 loci associated with $\mathrm{FEV}_{1} /$ FVC and 10 loci associated with $\mathrm{FEV}_{1}$ ) [17-19] in genome wide association studies explain only around 3\% of the variance in $\mathrm{FEV}_{1} / \mathrm{FVC}$ and around $1.5 \%$ of the variance in $\mathrm{FEV}_{1}$ [18]. Furthermore, the mean age of Cohorts for Heart and Aging Research in Genomic Epidemiology (CHARGE)/SpiroMeta consortia was 55 years; hence, it identified genes for lung function among older adults. Since findings from the LLFS [12] and a previous study [13] suggest that there may be genetic determinants of lung function among exceptionally long lived individuals and families, we conducted a genome wide association and linkage study among participants of the LLFS, a family based cohort of exceptional longevity, to identify novel genetic determinants of lung function in this unique sample.

\section{Material and methods}

\section{Cohort description and study design}

The LLFS study design has also been described in detail previously [12]. Briefly, the LLFS is a family-based cohort study $(\mathrm{n}=4,559)$ that enrolled long-lived probands and their siblings $(n=1,445)$, their offspring $(n=2,329)$ and spousal controls $(n=785)$ recruited from 3 U.S. field centers (Boston University Medical Center in Boston MA, Columbia College of Physicians and Surgeons in New York City NY, and the University of Pittsburgh in Pittsburgh PA) and the University of Southern Denmark to identify genetic determinants of longevity in these families. At the U.S. field centers, an initial recruitment brochure was mailed to all people in the Center for Medicare and Medicaid Services list of Medicare enrollees who were $\geq 89$ years old on January 1, 2005, were not in end stage renal disease or hospice programs and lived in zip codes within 3 hours driving distance of one of the three U.S field centers. Mailings were conducted in collaboration with CMS and the NIA via an IntraAgency Agreement. Study participants were also recruited from the local communities using mailed brochures, posters, web-based media and newspaper advertisements as well as community presentations at churches and senior centers. Additional mailing lists were obtained through local government agencies or purchased public domain lists from commercial vendors. The University of Southern Denmark used the Danish National Register of Persons to identify individuals who were $\geq 90$ years during the study recruitment period without any restrictions on residence [20]. Only families who had the proband, at least one living sibling, and one of their living offspring (minimum family size of 3) with a Family Longevity Selection Score (FLoSS) of 7 or higher that correlates well with later-observed longevity [21] and gave informed consent and were willing to participate in the interview and examination including donating a blood sample were eligible to participate in this study. This strategy led to the enrollment of families with the greatest potential utility for phenotypic and genetic studies of exceptional survival in families. All research was performed in compliance with the Helsinki Declaration. Written informed consent was obtained from all enrollees. In a few cases of cognitive impairment, family members were enrolled via proxy consent, provided that the participant was able to express assent at the time of the examination. This study was approved by the Institutional Review Boards at all the institutions in the United States of America and Denmark.

After excluding $15 \%$ of the participants due to presence of non-European ancestry $(n=6)$, low quality spirometry (defined as 2 or more acceptable spirometry maneuvers with reproducibility within $250 \mathrm{~mL})(\mathrm{n}=295)$, selfreported pulmonary fibrosis $(n=11)$ obtained during an in-person interview, history of lung volume reduction surgery $(n=14)$, or missing genotypes $(n=344)$, a total of 3,889 participants were included in the present analysis.

\section{Lung function measurements}

The examinations were conducted in the home setting with portable equipment by centrally trained and certified research assistants using a standardized protocol. Lung function was measured with a portable spirometer (EasyOne Diagnostic, NDD Medical Technologies, Andover, MA) following American Thoracic Society guidelines [22]. Calibration checks and the best 3 maneuvers were reviewed centrally by one investigator. Only spirometry tests with 2 or more acceptable maneuvers with reproducibility within $250 \mathrm{~mL}$ were selected for further data analyses.

\section{Genotyping and imputation}

The Human Omni chip 2.5 v1 (Illumina Inc., Ca), was used to genotype all the LLFS participants at the Center for Inherited Disease Research (CIDR). Ancestry principal components (PCs), to control for population structure, were produced with EIGENSTRAT [23] on 1,515 LLFS unrelated individuals using 120,093 tag SNPs, where in advance any SNPs with minor allele frequencies (MAF) $<5 \%$, Hardy Weinberg Equilibrium (HWE) $p<1 \mathrm{E}-06$, and with missing genotypes were excluded. Ancestry PCs produced from unrelated subjects were expanded, within EIGENS TRAT framework, to all members of LLFS. Genotype imputations were performed based on the cosmopolitan phased haplotypes of 1000 Human Genome (1000HG, version 2010-11 data freeze, 2012-03-04 haplotypes) using MACH and MINIMACH $[24,25]$ and a total of 38,045,518 SNPs were imputed. When MAF $\geq 0.05$ and $\mathrm{r}^{2}>0.3$ for imputed SNP filters were applied to the hybrid dataset for 
analysis, the number of SNPs for analysis is reduced to $6,522,421$ (from a total of 38,245,546 SNPs), of which 1,204,935 SNPs were genotyped and 5,317,486 SNPs were imputed.

\section{Statistical analysis}

The statistical models used to test the association between the GWAS SNPs and lung function $\left(\mathrm{FEV}_{1}\right.$ and $\mathrm{FEV}_{1} / \mathrm{FVC}$ ) were identical to the models used by the CHARGE/SpiroMeta consortia [18], except that the LLFS study also included adjustment for kinship structure to facilitate replication of results in the CHARGE/ SpiroMeta consortia. We employed a linear mixed effects model which adjusted for age, age ${ }^{2}$, sex, height, field center and ancestry PCs (PC1-20) in addition to the kinship matrix. The adjusted phenotypic residuals from these models $\left(\mathrm{FEV}_{1}\right.$ and $\left.\mathrm{FEV}_{1} / \mathrm{FVC}\right)$ were inverse normal transformed to normally distributed $z$-scores. These transformed residuals were then used as the phenotype for association testing under an additive genetic model, separately for ever smokers and never smokers. The associations between individual SNPs the $\mathrm{FEV}_{1}$ (milliliters) and $\mathrm{FEV}_{1} / \mathrm{FVC}$ (percent) were analyzed using a linear mixed effects model with kinship structure [26,27] to adjust for family relationships separately for ever smokers and never smokers. The effect estimates and standard errors for eversmokers and never smokers were meta-analyzed using inverse-variance weighting.

We used the same criteria as the CHARGE/SpiroMeta consortia for assessing genetic associations [18]. All SNPs that showed a borderline association $(\mathrm{p}<5 \mathrm{E}-06)$ with $\mathrm{FEV}_{1}$ and $\mathrm{FEV}_{1} / \mathrm{FVC}$ in LLFS were evaluated for their association with $\mathrm{FEV}_{1}$ and $\mathrm{FEV}_{1} / \mathrm{FVC}$ in the CHARGE/SpiroMeta consortia [18] using statistical models identical to those described above (individual family-based studies within the CHARGE/SpiroMeta did adjust for kinship structure while other studies within the consortia did not adjust for kinship structure). Finally, genotypes from both LLFS and CHARGE/SpiroMeta were meta-analyzed using METAL to evaluate the overall association between individual SNPs and lung function in both studies. We also evaluated the replication of previously reported GWAS hits (from the CHARGE/SpiroMeta consortia) for $\mathrm{FEV}_{1}$ and $\mathrm{FEV}_{1} / \mathrm{FVC}$ in the LLFS population using the statistical models described above.

To calculate Identity by Descent (IBD) for the linkage analyses, the ZAPLO program was used to estimate haplotypes of SNPs in small regions (0.5 cM intervals) [28]. The deCODE map was used to approximate the cM positions [29]. We identified all SNPs in our GWAS scan with no Mendel inconsistencies and an average pedigree heterozygosity $\geq 0.1$. Within each $0.5 \mathrm{cM}$ interval we used the first five such SNPs to construct a haplotype and if there were fewer than 5, we took all such SNPs in the interval. With the resulting haplotypes, IBD at $1 \mathrm{cM}$ intervals was estimated in the Loki program [30], which does chromosome-wide IBD estimation in intact pedigrees. These IBD estimates were then used in the SOLAR package [31] to conduct a variance-component linkage analysis. In the linkage analysis, we used the residuals of the $\mathrm{FEV}_{1}$ and $\mathrm{FEV}_{1} / \mathrm{FVC}$ phenotypes, adjusted for age, sex, height, ancestry PCs, smoking status (current, former, never), pack-years, and field center. The SOLAR package was also used to estimate heritability and empirical $p$ of LOD.

\section{Results}

There were 1,734 (45\%) male participants and 2155 (55\%) female participants with an average age of 68.6 years (standard deviation: 15.2 years) and an average BMI of $27.13 \mathrm{~kg} / \mathrm{m}^{2}$ (standard deviation: $4.79 \mathrm{Kg} / \mathrm{m}^{2}$ ). There were 2,203 (57\%) never smokers, 1,403 (40\%) former smokers and $283(3 \%)$ current smokers. The average number of cigarettes smoked among former smokers was 20.26 pack years (standard deviation: 22.07 pack years) while the average number of cigarettes smoked among current smokers was 28.25 pack years (standard deviation:19.03 pack years). There were 89 participants (2.3\%) with selfreported history of chronic obstructive pulmonary disease (COPD) and 339 (8.7\%) participants with self-reported history of asthma, 123 (3.1\%) participants with a selfreported history of congestive heart failure and $11(0.28 \%)$ participants with a self reported history of lung cancer. As shown in Table 1, the LLFS population was significantly older $(68.6 \pm 15.2$ years vs. $53.5 \pm 7.7$ years; $\mathrm{p}<0.0001)$ and had significantly higher percent never-smokers $(57 \%$ vs. $42 \% ; \mathrm{p}<0.0001$ ) as compared to CHARGE/SpiroMeta consortia. In addition, LLFS had slightly lower $\mathrm{FEV}_{1}$ (2455 ml vs. 2963; p < 0.0001) and $\mathrm{FEV}_{1} / \mathrm{FVC}(0.76$ vs. 0.78; $\mathrm{p}<0.0001$ ) as compared to the CHARGE/SpiroMeta consortia (Table 1).

We evaluated 6,522,421 SNPs across 3,889 individuals. The Q-Q plots for $\mathrm{FEV}_{1}$ and $\mathrm{FEV}_{1} / \mathrm{FVC}$ are shown in Additional file 1: Figures S1a and S1b respectively, while the Manhanttan plots for $\mathrm{FEV}_{1}$ and $\mathrm{FEV}_{1} / \mathrm{FVC}$ are shown in Additional file 1: Figures S2a and S2b respectively. Overall, we found 130 SNPs (23 genotyped SNPs and 107 imputed SNPs) that showed borderline association with $\mathrm{FEV}_{1}(\mathrm{p}<5 \mathrm{E}-06)$ (Additional file 2: Table S1) and 74 SNPs (14 genotyped SNPs and 60 imputed SNPs) that showed borderline association with $\mathrm{FEV}_{1} / \mathrm{FVC}$ $(\mathrm{p}<5 \mathrm{E}-06)$ (Additional file 2: Table S2). There was one SNP, rs71374110 in the ANKRD11 gene that showed a borderline association with both $\mathrm{FEV}_{1}$ and $\mathrm{FEV}_{1} / \mathrm{FVC}$ (Additional file 2: Tables S1 and S2). Among the GWAS SNPs with borderline association, 49 SNPs for $\mathrm{FEV}_{1}$ and $28 \mathrm{SNPs}$ for $\mathrm{FEV}_{1} / \mathrm{FVC}$ were available for replication in the CHARGE/SpiroMeta dataset (Additional file 2: Tables 
Table 1 Comparison of demographic and lung function variables ${ }^{*}$ in LLFS and CHARGE/SpiroMeta consortia ${ }^{+}$

\begin{tabular}{llll}
\hline & LLFS $(\mathbf{n}=\mathbf{3 8 8 9})$ & CHARGE/SpiroMeta $(\mathbf{n}=\mathbf{4 8 2 0 1})$ & $\mathbf{p}$ value \\
\hline Age (years) & $68.6(15.2)$ & $53.5(7.7)$ & $<0.0001$ \\
Sex (\% Male) & 44 & 44 & 0.62 \\
Smoking Status (\% never smoker) & 56.6 & 42.0 & $<0.0001$ \\
FEV $_{1}(\mathrm{ml})$ & $2455(866)$ & $2963(798)$ & $<0.0001$ \\
FEV 1 FVC & $0.76(0.07)$ & $0.78(0.09)$ & $<0.0001$ \\
\hline
\end{tabular}

"Values are means (standard deviations in parentheses) or percentages.

${ }^{+}$Values for the demographic and lung function variables in the CHARGE/SpiroMeta consortia were calculated using previously published data (Additional file 2: Table S1 a in Soler Artigas et al.) [18].

S3 and S4 respectively). The results for the GWAS SNPs with $\mathrm{p}<9.0 \mathrm{E}-07$ are presented in Tables 2 and 3 and the data for all SNPs are presented in Additional file 2: Tables S1 and S2. As shown in Table 2, rs1493131 in the CYP2U1 gene showed borderline association with $\mathrm{FEV}_{1}(\mathrm{p}=7.4 \mathrm{E}$ 07). In addition, 7 imputed SNPs in the CYP2U1 gene and 1 imputed SNP in the PHACTR2 gene also showed a borderline association with $\mathrm{FEV}_{1}(\mathrm{p}<9.2 \mathrm{E}-07)$. However, none of these SNPs were associated with $\mathrm{FEV}_{1}$ in the CHARGE/ SpiroMeta consortia or in the overall meta-analysis. Five of the 9 previously identified GWAS SNPs $(\mathrm{p}<1 \mathrm{E}-07)$ for $\mathrm{FEV}_{1}$ were nominally associated with $\mathrm{FEV}_{1}$ in LLFS $(\mathrm{p}<0.05)$ (Additional file 2: Table S5). For $\mathrm{FEV}_{1} / \mathrm{FVC}$, one SNP, rs889574 in the ANKRD11 gene, demonstrated a borderline association $(\mathrm{p}=1.6 \mathrm{E}-07)$ in the LLFS GWAS, (Table 3). Seven of 22 previously identified GWAS SNPs $(\mathrm{p}<1 \mathrm{E}-07)$ were also associated with $\mathrm{FEV}_{1} / \mathrm{FVC}$ in the LLFS $(\mathrm{p}<0.05)$ (Additional file 2: Table S6). A complete list of all SNPs associated with lung function $(\mathrm{p}<5 \mathrm{E}-06)$ is shown in Additional file 2: Tables S1 and S2, with their annotation and quality control information.

The heritability of $\mathrm{FEV}_{1}$ and $\mathrm{FEV}_{1} / \mathrm{FVC}$ as estimated by the SOLAR package was $0.37 \pm 0.043$ and $0.34 \pm 0.040$ respectively in the LLFS. The highest LOD score obtained for $\mathrm{FEV}_{1}$ was 3.33 localized to $28 \mathrm{cM}$ (chr 6: $9275152 \mathrm{bp}-$ $9467267 \mathrm{bp}$ ) at the q terminus of chromosome 6 (Figure 1). This locus remained significant $(\mathrm{LOD}=3.18)$ even after adjustment for 3 GWAS SNPs/indels located between $26 \mathrm{cM}-34 \mathrm{cM}$ on chromosome 6 and were nominally associated with $\mathrm{FEV}_{1}(\mathrm{p}<0.001)$ (Additional file 2: Table S7). A more comprehensive adjustment for 19 GWAS SNPs that were nominally associated with $\mathrm{FEV}_{1}(\mathrm{p}<1 \mathrm{E}-03)$ over a larger range $(10 \mathrm{cM}-50 \mathrm{cM})$ further attenuated the linkage peak $(\mathrm{LOD}=2.60)$ but did not completely explain the linkage peak (Additional file 2: Table S7). The highest LOD score obtained for $\mathrm{FEV}_{1} / \mathrm{FVC}$ was 3.29 localized to $219 \mathrm{cM}$ in chromosome 2 (chr 2: $217963480 \mathrm{bp}-$ 218313210 bp) (Figure 2). This locus did not remain significant (LOD $=2.2$ ) after adjustment for 10 GWAS SNPs located between $217 \mathrm{cM}-236 \mathrm{cM}$ nominally associated with $\mathrm{FEV}_{1} / \mathrm{FVC}(\mathrm{p}<0.001)$ (Additional file 2: Table S7) and was almost completely explained (LOD: 1.01) by adjustment of GWAS SNPs $(\mathrm{n}=38)$ in a broad region from
200-250 cM that were associated with $\mathrm{FEV}_{1} / \mathrm{FVC}(\mathrm{p}<$ 0.001) (Additional file 2: Table S7). Further adjustment for additional covariates such as age ${ }^{2}$, height ${ }^{2}, \mathrm{BMI}$, for self-reported COPD/asthma and those who took asthma/ COPD/bronchitis medications did not significantly change results of the linkage analyses Additional file 1: Figures S3a and S3b.

\section{Discussion}

This study identified a novel linkage peak in chromosome 2 for $\mathrm{FEV}_{1} / \mathrm{FVC}$ and confirmed a previously identified linkage peak in chromosome 6 for $\mathrm{FEV}_{1}$. This study also replicated some of the GWAS SNPs identified in previous studies. Though this study identified SNPs in the CYP2U1 and PHACTR2 genes that were associated with $\mathrm{FEV}_{1}$, these findings could not be replicated in independent datasets.

Two previous reports identified a linkage peak for $\mathrm{FEV}_{1}$ at the same locus (chromosome 6 at $28 \mathrm{cM}(\sim 280 \mathrm{~kb}))$ as the present study $[32,33]$. As compared to previous linkage studies we had improved marker density (average marker spacing $=0.5 \mathrm{cM}$ ) and improved accuracy by using haplotype-based IBD estimation. The availability of GWAS data also allowed us to evaluate whether GWAS SNPs under the linkage peak explained the linkage peak identified for $\mathrm{FEV}_{1}$. While we found a modest attenuation of the $\mathrm{FEV}_{1}$ linkage peak after adjustment for common GWAS SNPs under the linkage peak that were nominally associated with $\mathrm{FEV}_{1}(\mathrm{p}<0.001)$, they did not completely explain the linkage peak. In contrast, the novel linkage peak identified in chromosome 2 at $219 \mathrm{cM}(\sim 372 \mathrm{~kb})$ for $\mathrm{FEV}_{1} / \mathrm{FVC}$ was almost completely explained, by adjustment for the common GWAS SNPs under the linkage peak that were nominally associated with $\mathrm{FEV}_{1} / \mathrm{FVC}$ $(p<0.001)$. These findings suggest that common variants alone are insufficient to explain some linkage peaks such as the linkage peak in chromosome 6 for $\mathrm{FEV}_{1}$. As shown in other diseases, the inability to identify association under linkage peaks could in part be attributable to the fact that only common variants are examined under the linkage peak whereas the linkage signal could be caused by multiple rare variants with higher penetrance [34]. Hence, the contribution of multiple rare variants with high penetrance 
Table 2 GWAS findings for FEV F $_{1}$ in the LLFS $(p<1 E-07)$ and replication in the CHARGE/SpiroMeta consortia

\begin{tabular}{|c|c|c|c|c|c|c|c|c|c|c|c|c|c|c|}
\hline \multicolumn{7}{|c|}{ LLFS } & \multicolumn{3}{|c|}{ CHARGE/SPIROMETA CONSORTIA } & \multicolumn{5}{|c|}{ META ANALYSIS } \\
\hline SNP & $\begin{array}{l}\text { Chromosomal } \\
\text { position }\end{array}$ & Gene & $\begin{array}{l}\text { Coded/non- } \\
\text { coded allele }\end{array}$ & $\begin{array}{l}\text { Coded allele } \\
\text { frequency }\end{array}$ & $\beta$ (SE) & P_value & $\begin{array}{l}\text { Coded allele } \\
\text { frequency }\end{array}$ & $\beta$ (SE) & P_value & $\begin{array}{l}\text { Coded allele } \\
\text { frequency }\end{array}$ & $\beta$ (SE) & P_value & HetPVal & $\mathbf{N}$ \\
\hline rs9390140 & Chr 6: 144127026 & PHACTR2 & $\mathrm{C} / \mathrm{G}$ & 0.33 & $\begin{array}{l}-0.121 \\
(0.025)\end{array}$ & 8.83E-07 & 0.33 & $\begin{array}{l}0.002 \\
(0.008)\end{array}$ & 0.78 & 0.33 & $\begin{array}{l}-0.008 \\
(0.007)\end{array}$ & 0.25 & $1.80 \mathrm{E}-06$ & 51073 \\
\hline rs1493126 & Chr 4:108855828 & CYP2U1 & $\mathrm{C} / \mathrm{G}$ & 0.23 & $\begin{array}{l}0.139 \\
(0.028)\end{array}$ & $8.24 \mathrm{E}-07$ & 0.22 & $\begin{array}{l}-0.005 \\
(0.009)\end{array}$ & 0.53 & 0.22 & $\begin{array}{l}0.007 \\
(0.008)\end{array}$ & 0.42 & $9.48 \mathrm{E}-07$ & 51687 \\
\hline rs $4956031^{*}$ & Chr4: 108857140 & CYP2U1 & $\mathrm{T} / \mathrm{C}$ & 0.23 & $\begin{array}{l}0.138 \\
(0.028)\end{array}$ & $9.17 \mathrm{E}-07$ & 0.22 & $\begin{array}{l}-0.005 \\
(0.009)\end{array}$ & 0.52 & 0.22 & $\begin{array}{l}0.007 \\
(0.008)\end{array}$ & 0.43 & $1.04 \mathrm{E}-06$ & 51715 \\
\hline rs998405 & Chr4: 108862837 & CYP2U1 & $\mathrm{C} / \mathrm{G}$ & 0.23 & $\begin{array}{l}0.139 \\
(0.028)\end{array}$ & 7.93E-07 & 0.22 & $\begin{array}{l}-0.006 \\
(0.009)\end{array}$ & 0.50 & 0.22 & $\begin{array}{l}0.006 \\
(0.008)\end{array}$ & 0.43 & $8.18 \mathrm{E}-07$ & 51501 \\
\hline rs17564501 & Chr4: 108863209 & CYP2U1 & $A / C$ & 0.77 & $\begin{array}{l}-0.139 \\
(0.028)\end{array}$ & 7.93E-07 & 0.78 & $\begin{array}{l}0.006 \\
(0.009)\end{array}$ & 0.50 & 0.78 & $\begin{array}{l}-0.006 \\
(0.008)\end{array}$ & 0.44 & $8.15 \mathrm{E}-07$ & 51456 \\
\hline rs1493122 & Chr4: 108864651 & CYP2U1 & $\mathrm{T} / \mathrm{C}$ & 0.77 & $\begin{array}{l}-0.139 \\
(0.028)\end{array}$ & 7.59E-07 & 0.79 & $\begin{array}{l}0.006 \\
(0.009)\end{array}$ & 0.47 & 0.78 & $\begin{array}{l}-0.006 \\
(0.008)\end{array}$ & 0.46 & 7.40E-07 & 51105 \\
\hline rs1493131* & Chr4: 108860906 & CYP2U1 & $A / G$ & 0.23 & $\begin{array}{l}0.139 \\
(0.028)\end{array}$ & 7.37E-07 & 0.22 & $\begin{array}{l}-0.006 \\
(0.009)\end{array}$ & 0.47 & 0.22 & $\begin{array}{l}0.006 \\
(0.008)\end{array}$ & 0.46 & $7.23 \mathrm{E}-07$ & 51877 \\
\hline rs11724895 & Chr4: 108865791 & CYP2U1 & $C / G$ & 0.77 & $\begin{array}{l}-0.139 \\
(0.028)\end{array}$ & $7.72 \mathrm{E}-07$ & 0.79 & $\begin{array}{l}0.006 \\
(0.009)\end{array}$ & 0.46 & 0.78 & $\begin{array}{l}-0.006 \\
(0.008)\end{array}$ & 0.47 & 8.06E-07 & 51068 \\
\hline rs17564543 & Chr4: 108863481 & CYP2U1 & $\mathrm{T} / \mathrm{C}$ & 0.77 & $\begin{array}{l}-0.138 \\
(0.028)\end{array}$ & 9.07E-07 & 0.78 & $\begin{array}{l}0.007 \\
(0.009)\end{array}$ & 0.40 & 0.78 & $\begin{array}{l}-0.005 \\
(0.008)\end{array}$ & 0.53 & 7.47E-07 & 50935 \\
\hline
\end{tabular}

*These SNPs were genotyped using the Human Omni chip 2.5 v1 (Illumina Inc., Ca). Other SNPs were imputed. 
Table 3 GWAS findings for FEV 1 /FVC in the LLFS ( $p<1 E-07$ ) and replication in the CHARGE/SpiroMeta consortia

\begin{tabular}{|c|c|c|c|c|c|c|c|c|c|c|c|c|c|c|}
\hline \multicolumn{7}{|c|}{ LLFS } & \multicolumn{3}{|c|}{ CHARGE/SPIROMETA CONSORTIA } & \multicolumn{5}{|c|}{ META ANALYSIS } \\
\hline SNP & $\begin{array}{l}\text { Chromosomal } \\
\text { position }\end{array}$ & Gene & $\begin{array}{l}\text { Coded/non- } \\
\text { coded allele }\end{array}$ & $\begin{array}{l}\text { Coded allele } \\
\text { frequency }\end{array}$ & $\beta$ (SE) & $\overline{P \_ \text {value }}$ & $\begin{array}{l}\text { Coded allele } \\
\text { frequency }\end{array}$ & $\beta$ (SE) & $\overline{P \_ \text {value }}$ & $\begin{array}{l}\text { Coded allele } \\
\text { frequency }\end{array}$ & $\beta$ (SE) & P_value & HetPVal & $\mathrm{N}$ \\
\hline rs889574* & Chr16: 89386808 & ANKRD11 & $\mathrm{T} / \mathrm{C}$ & 0.31 & $\begin{array}{l}0.129 \\
(0.025)\end{array}$ & $1.63 \mathrm{E}-07$ & 0.34 & $\begin{array}{l}0.003 \\
(0.007)\end{array}$ & 0.67 & 0.66 & $\begin{array}{l}-0.013 \\
(0.007)\end{array}$ & 0.06 & 9.99E-07 & 50425 \\
\hline
\end{tabular}

*These SNPs were genotyped using the Human Omni chip 2.5 v1 (Illumina Inc., Ca). Other SNPs were imputed. 


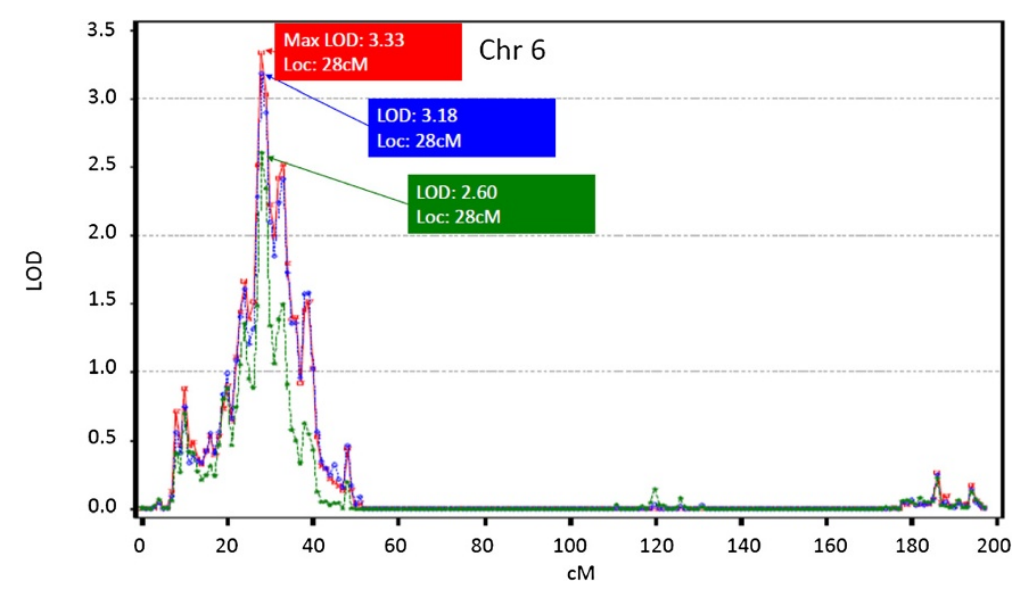

Figure 1 Linkage peaks on chromosome 6 associated with FEV $_{1}$ before and after adjustment for GWAS SNPs under the linkage peak associated with FEV $\mathbf{1}_{\mathbf{1}}$. Original linkage is in red, the linkage in blue is for adjustment of GWAS SNPs $(n=3)$ in a narrow region from 26-34 cM that were associated with $p<1 \mathrm{E}-03$, and green is the linkage after adjustment of GWAS SNPs $(n=19)$ in a broad region from $10-50 \mathrm{cM}$ that were associated with $\mathrm{p}<1 \mathrm{E}-03$.

under the linkage peak towards $\mathrm{FEV}_{1}$ needs to be evaluated in future studies. The linkage peak identified in chromosome 6 at $28 \mathrm{cM}(\sim 280 \mathrm{~kb})$ for $\mathrm{FEV}_{1}$ does not contain any known genes. However, there are several DNase I hypersensitivity sites and putative transcription factor binding sites (9H3K27Ac marks) that have been identified in cells from pulmonary epithelium and blood vessels derived from the pulmonary artery within this linkage peak (EnCode data) suggesting that regulatory elements in this region may play an important role in determining lung function. The linkage peak for $\mathrm{FEV}_{1} / \mathrm{FVC}$ in chromosome 2 at $219 \mathrm{cM}(\sim 373 \mathrm{~kb})$ contains the genomic region that codes for the DIRC3 gene, a non coding RNA that is involved in the pathogenesis of familial renal cancers (EnCode data). Though DIRC3 is expressed in pulmonary tissue its role in determining lung function has not been evaluated. Furthermore, this region also contains DNase I hypersensitivity sites or putative transcription factor binding sites (9H3K27Ac marks) in cells derived from the pulmonary epithelium or vasculature. Thus the linkage peaks identified in this study on chromosomes 2 and 6 may indicate previously unidentified regulatory pathways that may influence longevity through their effect on lung function.

Though this study identified a few novel GWAS SNPs that were associated with $\mathrm{FEV}_{1}$ and $\mathrm{FEV}_{1} / \mathrm{FVC}$, none of these findings could be replicated in the CHARGE/Spiro

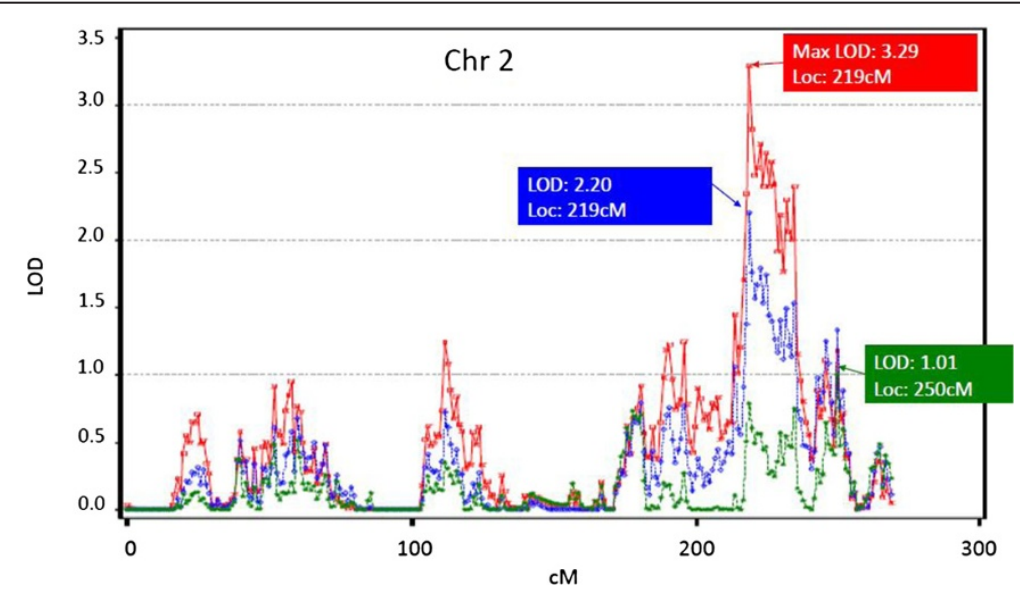

Figure 2 Linkage peaks on chromosome 2 associated with FEV $_{1} /$ FVC before and after adjustment for GWAS SNPs under the linkage peak associated with $\mathrm{FEV}_{\mathbf{1}} / \mathrm{FVC}$. Original linkage is in red, the linkage in blue is for adjustment of GWAS SNPS $(n=10)$ in a narrow region from 217-236 cM that were associated with $p<1 \mathrm{E}-03$, and green is the linkage after adjustment of GWAS SNPS $(n=38)$ in a broad region from 200-250 cM that were associated with $p<1 \mathrm{E}-03$. 
Meta consortia. However, only 38\% of SNPs associated with $\mathrm{FEV}_{1}$ or $\mathrm{FEV}_{1} / \mathrm{FVC}$ in LLFS were available for replication in the CHARGE/SpiroMeta consortia. Thus, the remaining SNPs and insertion/deletions polymorphisms associated with $\mathrm{FEV}_{1}$ and $\mathrm{FEV}_{1} / \mathrm{FVC}$ in LLFS but not genotyped/imputed in the CHARGE/SpiroMeta consortia will need to be evaluated in future studies. Since the LLFS study participants were not randomly selected to represent the general population but were specifically selected for their family history of exceptional longevity, it is possible that there may be some unique genotypes associated with lung function that may not be replicated in studies that are more representative of the general population. One previous study showed that elderly male offspring (range: 65-89 years) with long lived parents (age at death of at least on parent $>80$ years) had $\mathrm{FEV}_{1}$ that was $330 \mathrm{ml}$ larger than $\mathrm{FEV}_{1}$ for male offspring with short lived parents even after controlling for smoking [13]. The findings of the present study along with previous findings [13] might indicate that long lived families have unique genetic variants that contribute to higher lung function among those with exceptional longevity. This study also replicated 12 of 31 GWAS hits for $\mathrm{FEV}_{1}$ and $\mathrm{FEV}_{1} / \mathrm{FVC}$ identified in previous meta-analysis (Additional file 2: Tables S5 and S6). The reasons for not confirming all previously identified variants in this study may include limited power, population specific genetic heterogeneity and differences in environmental exposures such as smoking. Genetic heterogeneity in contribution towards determination of lung function in elderly participants (average age among LLFS participants: 68.8 years) as compared to middle aged adults may also contribute to the differences in genetic association observed in the LLFS study as compared to previous studies. As shown in Additional file 2: Tables S3 and S4, several SNPs had highly significant $\mathrm{p}$ for heterogeneity between the LLFS and the CHARGE/SpiroMeta dataset supporting the idea that, at least for some loci, heterogeneity in genetic contribution may account for the lack of replication of certain loci.

\section{Conclusion}

The family-based cohort design of the LLFS with extensive genotype information and detailed lung function measurements makes this study a valuable resource to identify genetic determinants of lung function. In addition to confirming some of the previously identified GWAS SNPs and a previously identified linkage peak in chromosome 6 for $\mathrm{FEV}_{1}$, this study also identified a novel linkage peak in chromosome 2 for $\mathrm{FEV}_{1} / \mathrm{FVC}$. Repeated measurements of lung function in this study population along with targeted resequencing under the observed linkage peaks in future studies may help clarify the role of genetic variants in determining preserved lung function among exceptionally long lived individuals.

\section{Additional files}

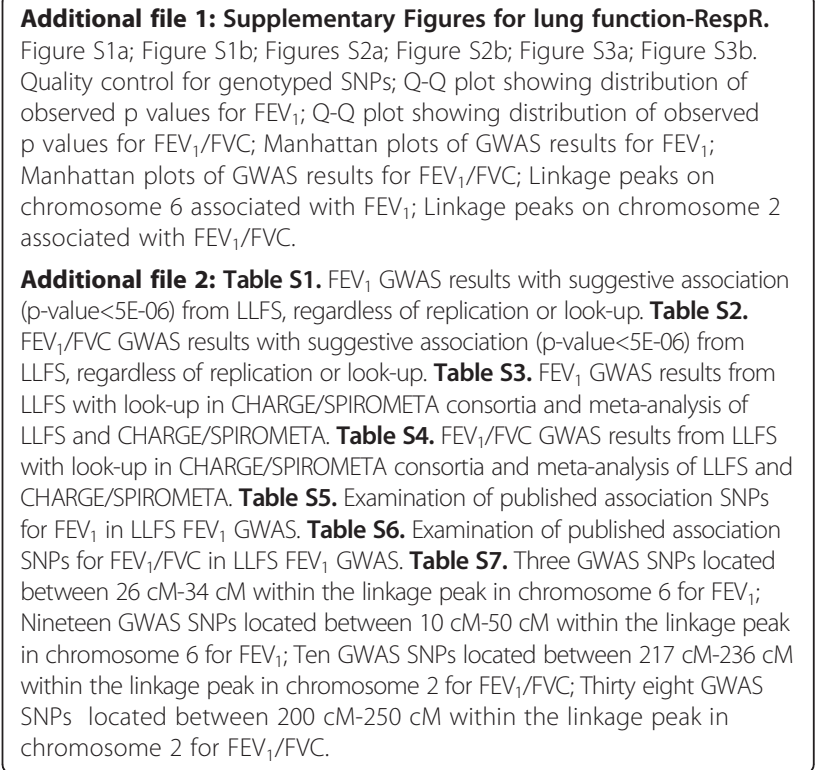

Competing interests

The authors declare that they have no competing interests.

\section{Authors' contributions}

BT participated in the design of the study, the data analysis, data interpretation and manuscript preparation. MW participated in the data analysis, data interpretation and manuscript preparation. RM, JS, LC and SB participated in the interpretation of the data and manuscript editing. RGB was involved in the Spirometry data collection and manuscript editing. Both the CHARGE and SpiroMeta consortia were involved in data replication in independent dataset and manuscript review. AN participated in the data analysis, data interpretation and manuscript review. All authors read and approved the final manuscript.

Authors' information

Cohorts for Heart and Aging Research in Genomic Epidemiology (CHARGE) consortium, SpiroMeta consortium.

\section{Acknowledgements}

The investigators thank LLFS participants and staff for their contributions.

\section{Author details}

1Department of Laboratory Medicine and Pathology, University of Minnesota, 515 Delaware Street SE, 1-136 Moos Towers, Minneapolis, MN 55455, USA. ${ }^{2}$ Department of Genetics, Division of Statistical Genomics, Washington University, 4444 Forest Park Parkway, CB\#8506, St. Louis, MO, USA. ${ }^{3}$ Department of Human Genetics, University of Pittsburgh, 728 Parran Hall, Pittsburgh, PA 15261, USA. ${ }^{4}$ Department of Epidemiology, Center for Aging and Population Health, University of Pittsburgh, 130 De Soto Street, Pittsburgh, PA 15261, USA. ${ }^{5}$ Department of Neurology, Columbia University, G.H. Sergievsky Center, 630 W 168th St, P\&S 16, New York, NY 10032, USA. ${ }^{6}$ Department of Epidemiology, Biostatistics and Biodemography, University of Southern Denmark, J. B. Winsløws Vej 9 B, st. th, 5000 Odense, C, Denmark. ${ }^{7}$ Department of Medicine, Columbia University Medical Center, PH 9 East, Room 105, New York, NY 10032, USA. ${ }^{8}$ Department of Epidemiology, Columbia University Medical Center, PH 9 East, Room 105, New York, NY 10032, USA.

Received: 8 July 2014 Accepted: 16 October 2014 Published online: 01 November 2014 


\section{References}

1. Hegewald MJCR: Pulmonary function testing. In Murray and Nadel's Textbook of Respiratory Medicine. 5th edition. Edited by Mason RJBV, Martin TR, et al. Philadelphia, Pa: Saunders Elsevier; 2010.

2. Ashley F, Kannel WB, Sorlie PD, Masson R: Pulmonary function: relation to aging, cigarette habit, and mortality. Ann Intern Med 1975, 82:739-745.

3. Beaty TH, Cohen BH, Newill CA, Menkes HA, Diamond EL, Chen CJ: Impaired pulmonary function as a risk factor for mortality. Am J Epidemiol 1982, 116:102-113.

4. Chinn S, Gislason T, Aspelund T, Gudnason V: Optimum expression of adult lung function based on all-cause mortality: results from the Reykjavik study. Respir Med 2007, 101:601-609.

5. Higgins MW, Keller JB: Predictors of mortality in the adult population of Tecumseh. Arch Environ Health 1970, 21:418-424.

6. Hole DJ, Watt GC, Davey-Smith G, Hart CL, Gillis CR, Hawthorne VM: Impaired lung function and mortality risk in men and women: findings from the Renfrew and Paisley prospective population study. BMJ 1996, 313:711-715. discussion 715-716.

7. Lange P, Nyboe J, Appleyard M, Jensen G, Schnohr P: Spirometric findings and mortality in never-smokers. J Clin Epidemiol 1990, 43:867-873.

8. Schunemann HJ, Dorn J, Grant BJ, Winkelstein W Jr, Trevisan M: Pulmonary function is a long-term predictor of mortality in the general population: 29-year follow-up of the Buffalo Health Study. Chest 2000, 118:656-664.

9. Sin DD, Wu L, Man SF: The relationship between reduced lung function and cardiovascular mortality: a population-based study and a systematic review of the literature. Chest 2005, 127:1952-1959.

10. Jacobsen PK, Sigsgaard T, Pedersen OF, Christensen K, Miller MR: Lung function as a predictor of survival in very elderly people: the Danish 1905 cohort study. J Am Geriatr Soc 2008, 56:2150-2152.

11. Hollenberg M, Yang J, Haight TJ, Tager IB: Longitudinal changes in aerobic capacity: implications for concepts of aging. J Gerontol A Biol Sci Med Sci 2006, 61:851-858.

12. Newman AB, Glynn NW, Taylor CA, Sebastiani P, Perls TT, Mayeux R, Christensen K, Zmuda JM, Barral S, Lee JH, Simonsick EM, Walston JD, Yashin Al, Hadley E: Health and function of participants in the long life family study: a comparison with other cohorts. Aging (Albany NY) 2011, 3:63-76.

13. Jedrychowski W: Effects of smoking and longevity of parents on lung function in the apparently healty elderly. Arch Gerontol Geriatr 1990, 10:19-26.

14. Givelber RJ, Couropmitree NN, Gottlieb DJ, Evans JC, Levy D, Myers RH, O'Connor GT: Segregation analysis of pulmonary function among families in the Framingham Study. Am J Respir Crit Care Med 1998, 157:1445-1451.

15. Wilk JB, Djousse L, Arnett DK, Rich SS, Province MA, Hunt SC, Crapo RO, Higgins M, Myers RH: Evidence for major genes influencing pulmonary function in the NHLBI family heart study. Genet Epidemiol 2000, 19:81-94.

16. Zhou JJ, Cho MH, Castaldi PJ, Hersh CP, Silverman EK, Laird NM: Heritability of chronic obstructive pulmonary disease and related phenotypes in smokers. Am J Respir Crit Care Med 2013, 188:941-947.

17. Hancock DB, Eijgelsheim M, Wilk JB, Gharib SA, Loehr LR, Marciante KD, Franceschini N, van Durme YM, Chen TH, Barr RG, Schabath MB, Couper DJ, Brusselle GG, Psaty BM, van Duijn CM, Rotter Jl, Uitterlinden AG, Hofman A, Punjabi NM, Rivadeneira F, Morrison AC, Enright PL, North KE, Heckbert SR, Lumley T, Stricker BH, O'Connor GT, London SJ: Meta-analyses of genomewide association studies identify multiple loci associated with pulmonary function. Nat Genet 2010, 42:45-52.

18. Soler Artigas M, Loth DW, Wain LV, Gharib SA, Obeidat M, Tang W, Zhai G, Zhao JH, Smith AV, Huffman JE, Albrecht E, Jackson CM, Evans DM, Cadby G, Fornage M, Manichaikul A, Lopez LM, Johnson T, Aldrich MC, Aspelund T, Barroso I, Campbell H, Cassano PA, Couper DJ, Eiriksdottir G, Franceschini N, Garcia M, Gieger C, Gislason GK, Grkovic I, et al: Genome-wide association and large-scale follow up identifies 16 new loci influencing lung function. Nat Genet 2011, 43:1082-1090.

19. Repapi E, Sayers I, Wain LV, Burton PR, Johnson T, Obeidat M, Zhao JH, Ramasamy A, Zhai G, Vitart V, Huffman JE, Igl W, Albrecht E, Deloukas P, Henderson J, Granell R, McArdle WL, Rudnicka AR, Wellcome Trust Case Control Consortium, Barroso I, Loos RJ, Wareham NJ, Mustelin L, Rantanen T, Surakka I, Imboden M, Wichmann HE, Grkovic I, Jankovic S, Zgaga L, et al: Genome-wide association study identifies five loci associated with lung function. Nat Genet 2010, 42:36-44.
20. Pedersen CB, Gotzsche H, Moller JO, Mortensen PB: The Danish Civi Registration System. a cohort of eight million persons. Dan Med Bull 2006, 53:441-449.

21. Sebastiani P, Hadley EC, Province M, Christensen K, Rossi W, Perls T, Ash AS: A family longevity selection score: ranking sibships by their longevity, size, and availability for study. Am J Epidemiol 2009, 170:1555-1562.

22. Miller MR, Hankinson J, Brusasco V, Burgos F, Casaburi R, Coates A, Crapo R, Enright $P$, van der Grinten $C P$, Gustafsson $P$, Jensen $R$, Johnson DC, MacIntyre N, McKay R, Navajas D, Pedersen OF, Pellegrino R, Viegi G, Wanger J, ATS/ERS Task Force: Standardisation of spirometry. Eur Respir J 2005, 26:319-338.

23. Price AL, Patterson NJ, Plenge RM, Weinblatt ME, Shadick NA, Reich D: Principal components analysis corrects for stratification in genome-wide association studies. Nat Genet 2006, 38:904-909.

24. Li Y, Willer C, Sanna S, Abecasis G: Genotype imputation. Annu Rev Genomics Hum Genet 2009, 10:387-406.

25. Li Y, Willer CJ, Ding J, Scheet P, Abecasis GR: MaCH: using sequence and genotype data to estimate haplotypes and unobserved genotypes. Genet Epidemiol 2010, 34:816-834

26. Pinheiro JC, Bates D: Mixed-effects models in S and S-Plus. New York: Springer; 2000.

27. Cortinas Abrahautes J, Burzykowski T: A version of the EM algorithm for proportional hazards models with random effects. In Lecture Notes of the ICB Seminars. 2002:15-20

28. O'Connell JR: Zero-recombinant haplotyping: applications to fine mapping using SNPs. Genet Epidemiol 2000, 19(Suppl 1):S64-S70.

29. Kong A, Thorleifsson G, Gudbjartsson DF, Masson G, Sigurdsson A, Jonasdottir A, Walters GB, Jonasdottir A, Gylfason A, Kristinsson KT, Gudjonsson SA, Frigge ML, Helgason A, Thorsteinsdottir U, Stefansson K: Fine-scale recombination rate differences between sexes, populations and individuals. Nature 2010, 467:1099-1103.

30. Heath SC: Markov chain Monte Carlo segregation and linkage analysis for oligogenic models. Am J Hum Genet 1997, 61:748-760.

31. Almasy $L$, Blangero J: Multipoint quantitative-trait linkage analysis in general pedigrees. Am J Hum Genet 1998, 62:1198-1211.

32. Joost O, Wilk JB, Cupples LA, Harmon M, Shearman AM, Baldwin CT, O'Connor GT, Myers RH, Gottlieb DJ: Genetic loci influencing lung function: a genome-wide scan in the Framingham Study. Am J Respir Crit Care Med 2002, 165:795-799.

33. Wilk JB, DeStefano AL, Joost O, Myers RH, Cupples LA, Slater K, Atwood LD, Heard-Costa NL, Herbert A, O'Connor GT, Gottlieb DJ: Linkage and association with pulmonary function measures on chromosome $6 \mathrm{q} 27$ in the Framingham Heart Study. Hum Mol Genet 2003, 12:2745-2751.

34. Eyre S, Ke X, Lawrence R, Bowes J, Panoutsopoulou K, Barton A, Thomson W, Worthington J, Zeggini E: Examining the overlap between genome-wide rare variant association signals and linkage peaks in rheumatoid arthritis. Arthritis Rheum 2011, 63:1522-1526.

\section{doi:10.1186/s12931-014-0134-x}

Cite this article as: Thyagarajan et al: Genetic variants associated with lung function: the long life family study. Respiratory Research 2014 15:134.

\section{Submit your next manuscript to BioMed Central and take full advantage of:}

- Convenient online submission

- Thorough peer review

- No space constraints or color figure charges

- Immediate publication on acceptance

- Inclusion in PubMed, CAS, Scopus and Google Scholar

- Research which is freely available for redistribution 